\title{
A identidade dialetal do "manezinho" com foco em características entonacionais
}

\author{
The "Manezinho" dialectal identity and its intonational features
}

\author{
Izabel Christine Seara \\ Juan Manuel Sosa \\ Universidade Federal de Santa Catarina - Florianópolis - Santa Catarina - Brasil
}

\author{
$\diamond$
}

\begin{abstract}
Resumo: O falar "manezinho" é um dialeto não urbano do português brasileiro falado na Ilha de Santa Catarina que apresenta certas propriedades segmentais e suprassegmentais que o definem. Neste artigo, investigamos uma dessas propriedades suprassegmentais caracterizada pelo uso de um contorno declarativo particular, que exibe uma acentuada subida tonal até a sílaba tônica final, seguida por uma queda do tom alto para a parte inferior do registro do falante. Usamos dados provenientes do Projeto VARSUL como corpora de pesquisa, analisando esses dados a partir de uma metodologia da fonética experimental. Por meio de dois experimentos de percepção, mostramos que o contorno em questão, em notação autossegmental métrica (LH) ¡HL\%, é reconhecido por um número muito significativo de ouvintes como sendo efetivamente o falar "manezinho". As implicações para a sociofonética são os detalhes fonéticos quantitativos da queda tonal final, que dão a este contorno sua singularidade frente a outros dialetos.
\end{abstract}

Palavras-chave: Entoação; Português brasileiro; Falar "manezinho"; Sociofonética

\begin{abstract}
Manezinho" is a non-urban dialect of Brazilian Portuguese spoken in the Island of Santa Catarina, which has certain defining segmental and suprasegmental properties. This paper investigates one of these suprasegmental properties characterized by the use of a particular declarative contour, which shows a sharp tonal rise up to the final stressed syllable, followed by a drop from the high tone to the lower part of the speaker's range. We used data from the VARSUL Project as research corpus, analyzing these data with the methodology of experimental phonetics. By means of two perception tests, we show that the contour in question, in autosegmental-metrical notation (LH) ¡HL\%, is recognized by a very significant number of listeners as being effectively "Manezinho". The implications for sociophonetics are the quantitative phonetic details of the final tonal fall, which give this contour its uniqueness over other dialects.
\end{abstract}

Keywords: Intonation; Brazilian Portuguese; "Manezinho"dialect; Sociophonetics

\section{Introdução}

Muito se fala das características diferenciadas de uma das variedades do falar florianopolitano: o falar do "manezinho". Esse termo é empregado aqui mais como um adjetivo afetuoso daqueles que conhecem e admiram esse falar por suas especificidades e não como um termo pejorativo. Esse falar é característico, principalmente, de regiões não urbanas de Florianópolis, a capital de Santa Catarina (FURLAN, 1989).

Este estudo constitui uma primeira contribuição sobre as características suprassegmentais do falar do interior da capital florianopolitana - o falar "manezinho".
Para nortear tal estudo, colocamo-nos a seguinte questão: seria o contorno entonacional, representado, nesse caso, pela curva da frequência fundamental (f0), o que mais caracterizaria o falar "manezinho"? As pessoas em geral, ao ouvirem essa variedade, apontam como características mais recorrentes a entoação e a velocidade da fala. Assim, iniciamos este estudo com dados selecionados a partir da percepção de falantes nativos ${ }^{1}$ que reconhecem, em partes do discurso do "manezinho", uma melodia ${ }^{2}$ que

\footnotetext{
O termo nativos se refere a falantes que nasceram e sempre viveram na cidade de Florianópolis - capital do estado de Santa Catarina.

2 Melodia aqui tem um sentido mais geral, como a modulação, a impressão perceptual da frequência fundamental (f0) desse falar.
} 
parece identificar esse falar, independentemente de suas características segmentais. Com esses dados levantados e analisados, elaboramos testes de percepção que buscaram verificar até que ponto o contorno entonacional caracterizaria esse falar.

Trata-se então de um estudo ainda introdutório e de cunho mais qualitativo. Para apresentá-lo, dividimos este artigo em quatro seções. Na Seção 1, faremos algumas considerações iniciais, necessárias à sua contextualização. $\mathrm{Na}$ Seção 2, serão apresentados os trechos selecionados como os mais característicos do contorno entonacional do falar "manezinho" com sua respectiva notação prosódica. Na Seção 3, a metodologia empregada nos experimentos perceptuais será detalhada e, na Seção 4, serão exibidos os resultados obtidos para, ao final, apresentarmos nossas conclusões acerca deste estudo.

\section{Contextualização da pesquisa}

A sociofonética enfoca as relações entre a forma fonético-fonológica e fatores sociais, regionais e interacionais-comunicativos. Este nosso estudo sociofonético procura descrever os efeitos de uma variação entonacional na percepção, categorização e identificação do falar "manezinho"; uma vez que o significado social dessa variação entonacional parece depreender identidades sociais localmente relevantes.

Utilizamos técnicas instrumentais e de laboratório para analisar os parâmetros fonéticos que atuam como indicadores sociais, considerando que o uso dessas técnicas auxiliam o estudo fonético-fonológico da variação no contínuo da fala. Alguns aspectos da dialetologia perceptual foram usados para o reconhecimento dos falares e para o julgamento dos falantes sobre as pistas de variação entonacional. Usamos configurações experimentais assim como observações informais de comportamento dos falantes nas entrevistas, além dos comentários dos sujeitos nos testes de percepção.

Apesar de sua ampla gama de variação, as mudanças entonacionais não têm sido objeto de estudo quando se trata de pesquisas variacionistas. Isso acontece, em parte, devido à sua intrincada complexidade e à sua estreita associação com significados pragmáticos e, também, pela dificuldade em estabelecer a equivalência funcional dos contornos entonacionais alternativos em amostras de dados constituídos por materiais não controlados. No entanto, a análise fonética demonstra que finos detalhes de contornos entonacionais (curvas de frequência fundamental) podem ser usados para a construção da identidade social. Igualmente é necessária uma modelagem dos contornos entonacionais, porque a sua medição requer a descrição da frequência fundamental (f0) no curso de tempo sobre um trecho particular do sinal de fala, para estimar os parâmetros pertinentes a partir do sinal acústico.

A abordagem acústico-perceptual, aplicada à presente pesquisa, vai nos permitir investigar o significado social do contorno entonacional, foco deste estudo. Veremos como a variação regional na fala indica a identidade geográfica das pessoas assim como a consciência dessa identidade, demostrando como algumas variações entonacionais são produzidas e percebidas no seu contexto social.

Por outro lado, os significados entonacionais compreendem várias vertentes de informações que refletem, dentre outras, a estrutura gramatical, a função pragmática do enunciado, as atitudes do falante e a intenção do falante ao produzir uma sentença. Para uma comparação produtiva, é preciso isolar e descrever cuidadosamente o uso e a função dos contornos sob observação. Podem não ser comparáveis, por exemplo, sentenças declarativas com sentido de continuidade, ou de finalidade, ou de exclamação. Por essa razão, para nossa análise, serão considerados somente os aspectos relativos às informações entonacionais presentes em sentenças que parecem refletir a identidade do falante.

\section{A constituição dos dados de análise do falar "manezinho"}

Os dados analisados foram coletados da base de dados do Projeto de Variação Linguística na Região Sul do Brasil (VARSUL) que se constitui de entrevistas coletadas em Santa Catarina, Paraná e Rio Grande do Sul. Selecionamos as nossas amostras depois da análise de várias dezenas de contornos entonacionais declarativos de um total de 10 informantes da região da Grande Florianópolis, capital de Santa Catarina (seis homens e quatro mulheres), e um homem e uma mulher de Porto Alegre, capital do estado do Rio Grande do Sul, como controle para experimentos de percepção. Nossa análise entonacional foi baseada em amostras extraídas de entrevistas de três informantes provenientes da região não urbana de Florianópolis.

A seleção do material a ser anotado prosodicamente passou pela percepção de nativos ${ }^{3}$, que apontavam trechos de entrevistas que, segundo eles, seriam rapidamente caracterizados como a melodia do falar "manezinho". A partir dessa seleção, fizemos a notação prosódica dos trechos selecionados e observamos que de 22 seleções, 17 eram caracterizadas por contornos entonacionais, anotados majoritariamente como $(\mathrm{LH}){ }_{i} \mathrm{H}^{*} \mathrm{~L} \%$ no modelo

\footnotetext{
Inclui-se, entre esses nativos, a primeira autora deste estudo que é falante nativa da variedade florianopolitana - urbana, e que reconhece as sentenças selecionadas como apresentando a melodia que caracteriza a variedade florianopolitana - não urbana, o falar "manezinho".
} 
autossegmental-métrico (SOSA, 2003; PRIETO, 2003; LADD, 2008; FROTA, PRIETO, 2015). Ocasionalmente, o contorno entonacional com a notação $\left(\mathrm{L}_{i} \mathrm{H}\right){ }_{i} \mathrm{H}^{*} \mathrm{~L} \%$ também era observado. Nesse contorno, há uma subida para o núcleo de aproximadamente uma oitava ${ }^{4}$, conforme curva de f0 e respectiva notação, exibidas na Figura 1. Nela, podemos observar como os valores de f0 sobem de $140 \mathrm{~Hz}$ até $338 \mathrm{~Hz}$, para na sequência cair para 174 $\mathrm{Hz}$. Isso mostra que a subida da curva de f0 é de mais de uma oitava, e a descida também é de praticamente uma oitava em um efeito upstep, que é representado com os diacríticos [i].

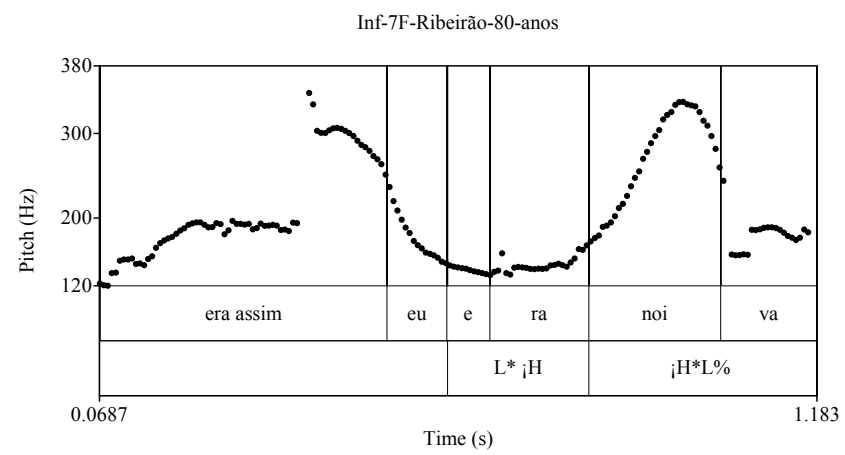

Figura 1. Curva de fo de uma informante feminina do falar "manezinho", camada de etiquetagem e notação prosódica do trecho Era assim, eu era noiva.

\subsection{0 contorno entonacional investigado}

A variável que isolamos é um contorno entonacional declarativo que parece característico do sotaque "manezinho". Pelo seu uso e valor indicial pode ser considerado uma verdadeira construção melódica, ou seja, um agrupamento de tons que são distintivos e significativos. As construções melódicas são unidades entonacionais com forma e sentido, e com uma especificação pragmática que inclui informação contextual linguística e comunicativa.

Foneticamente, o contorno entonacional observado, que recai sobre a sílaba tônica final - o núcleo entonacional - pode ser caracterizado como uma sequência ascendente pré-nuclear que sobe até um pico bastante alto seguido por uma drástica queda para a parte inferior do registro do falante. Na notação autossegmental-métrica, esse núcleo da frase entonacional poderia ser representado como $\left(\mathrm{L}^{*} \mathrm{H}\right){ }_{i} \mathrm{H}^{*} \mathrm{~L} \%$, e é este último o mais representativo da entoação do falar "manezinho". Esse contorno que funciona como um marcador regional contrasta com os contornos usados em outros dialetos, ou seja, com o padrão

\footnotetext{
4 Uma oitava corresponde ao dobro ou a metade da frequência fundamental de referência.
}

entonacional, apontado por pesquisadores brasileiros como o mais empregado no português brasileiro (PB) em tais contextos e para as declarativas finais, que seria o H+L*L\% (MORAES, 2008; NUNES, SEARA, 2011; NUNES, 2011; SEARA et al., 2011; SEARA, COUTO, 2011). Esse padrão mais recorrente no $P B$ apresenta o tom mais alto na sílaba átona pré-nuclear, seguido de uma queda na sílaba tônica continuando até o registro baixo.

A fim de indicar a singularidade desse marcador regional, seria necessário compará-lo com outras variedades, tentando responder às seguintes perguntas: Qual contorno ocorre, nos mesmos contextos, em outras variedades? Qual é a intenção, propósito ou o efeito deste contorno? É empregado para diferentes usos pragmáticos, ou com diferentes estruturas sintáticas? Os usos pragmáticos e semânticos deste tipo de unidade entonacional significativa serão investigados em estudos posteriores. Neste momento, nossa intenção é estabelecer: (i) que o contorno entonacional do falar "manezinho" é realmente um marcador de identidade; (ii) que é reconhecido pelos falantes como um traço que identifica o falar "manezinho"; (iii) que tem características fonéticas próprias.

No seu uso, o contorno entonacional observado parece ser uma declarativa com o sentido de finalizar uma dada situação, com um sentido de obviedade, de algo autoevidente, em que o falante se compromete ele/ela mesma com a condição de verdade da afirmação.

A configuração mais característica, o contorno mais recorrente que evidencia o falar "manezinho", é descrita na Figura 2 e na Figura 3, a seguir. Na Figura 2, é mostrado um outro exemplo de contorno do falar "manezinho" produzido por uma informante feminina cuja curva de f0 já foi exibida na Figura 1. Desta vez, a subida de f0 para o pico tonal na sílaba tônica vai de $168 \mathrm{~Hz}$ até $232 \mathrm{~Hz}$, caindo depois para $140 \mathrm{~Hz}$. Isto é, uma subida de quase 6 semitons, ou meia oitava, seguida pela descida de 9 semitons ou $3 / 4$ de oitava. A notação proposta para este contorno é $\mathrm{L} * \mathrm{H}{ }_{i} \mathrm{H}^{*} \mathrm{~L} \%$ com upstep na sílaba tônica.

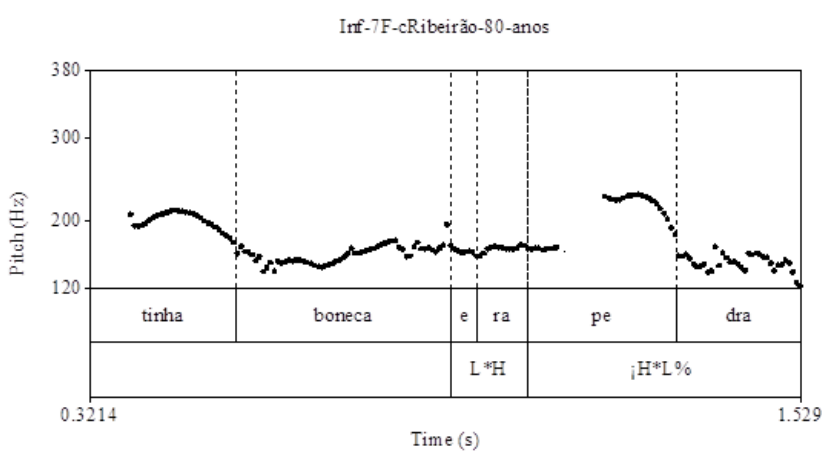

Figura 2. Curva de fo de uma informante feminina do falar "manezinho", camada de etiquetagem e notação prosódica do trecho Tinha boneca, era pedra. 
Na Figura 3, apresentamos o mesmo contorno, produzido agora por um informante masculino. Notamos que o desenho da curva de f0 também é o mesmo, com subida de um tom médio para um pico tonal alto, seguido de uma queda brusca de f0 até a base tonal do falante. Sem ser um enunciado propriamente exclamativo ou enfático, o movimento é bastante amplo: de $155 \mathrm{~Hz}$ sobe até $220 \mathrm{~Hz}$, e desce para $85 \mathrm{~Hz}$; ou seja, uma subida de seis semitons - meia oitava - e uma descida de 16 semitons, uma oitava e um ${ }^{1 / 3}$.

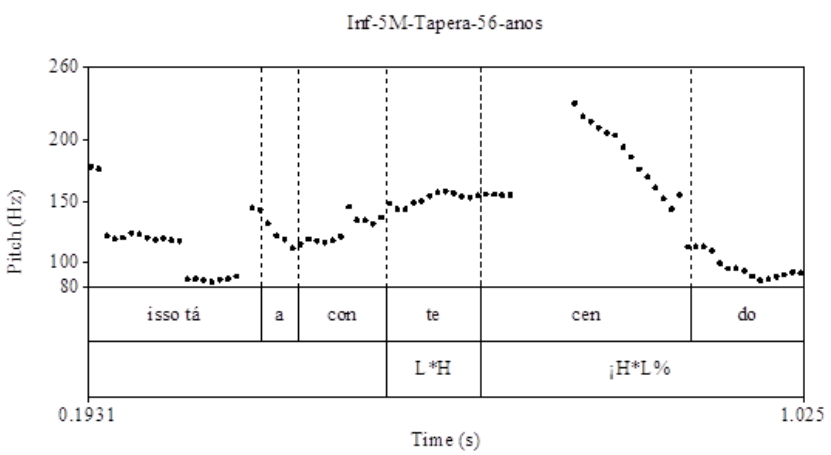

Figura 3. Curva de fo de um informante masculino do falar "manezinho", camada de etiquetagem e notação prosódica do trecho Isso tá acontecendo.

Finalmente, na Figura 4, mostramos o contorno considerado padrão nas declarativas neutras do $\mathrm{PB}$ (MORAES, 2008; NUNES, 2011; SEARA, COUTO, 2011; dentre outros), produzido pelo falante de Porto Alegre. Aqui o núcleo entonacional é o $\mathrm{H}+\mathrm{L} * \mathrm{~L} \%$. Nele, a maior altura tonal não está na sílaba tônica, mas sim na pré-tônica, que é seguida por uma queda tonal concentrada agora na sílaba tônica.

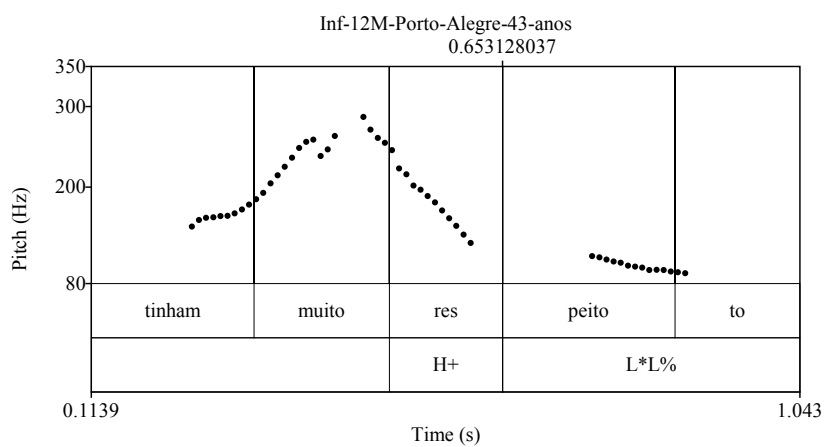

Figura 4. Curva de fo de um informante masculino de Porto Alegre, camada de etiquetagem e notação prosódica do trecho Tinham muito respeito.

Resumindo, podemos dizer que o contorno entonacional nuclear do falar "manezinho" está foneticamente composto por uma subida de cerca de meia oitava das sílabas pré-tônicas para as tônicas, partindo de um tom médio. Depois do pico alcançado, segue-se uma queda de cerca de uma oitava, até o registro baixo do falante. Esse achado, em nossa opinião, é o mais relevante, pois conseguimos identificar essa melodia que o falante executa e quais são os alvos tonais que ele/ela tenta alcançar idealmente.

Podemos concluir que a média dos tons mais altos e a média dos tons mais baixos, neste contorno entonacional nuclear, correspondem aos limites esperados do registro de um falante em uma fala sem ênfase; isto geralmente equivale a cerca de uma oitava centrada na média do falante (DE LOOZE, HIRST, 2014). O contorno entonacional do falar "manezinho" atesta este padrão de uso do registro tonal em ambas as direções (para cima e para baixo, partindo da sua média tonal), definido como a unidade de produção e percepção considerada como a mais psico-acusticamente natural, que é a oitava e suas frações.

\section{A metodologia para a montagem dos experimentos de percepção}

Depois de observada a presença, nos trechos selecionados, de curvas de fo que definiam o falar "manezinho" e que se diferenciavam das curvas encontradas em sentenças declarativas para outros dialetos, o objetivo era verificar se tal melodia seria também percebida por ouvintes de outros falares e por nativos de Florianópolis. Assim, montamos dois experimentos de percepção que foram realizados por nove ouvintes.

O primeiro experimento consistiu em um teste de identificação composto de 32 estímulos, sendo 22 referentes ao falar "manezinho" (S05, S07, S09), dentre estes, 17 daqueles caracterizados com contorno do falar "manezinho", especificado anteriormente, e cinco que não apresentavam tal contorno; e mais 10 estímulos distratores, compostos por sentenças de outros falares (S11 e S12). Os estímulos foram constituídos então de sentenças filtradas com um filtro passa banda (de $50 \mathrm{~Hz}$ a 300 ou $400 \mathrm{~Hz}$, dependendo do sexo) e, dessa forma, apenas as informações tonais eram ouvidas.

O segundo experimento também consistiu em um teste de identificação composto de 28 estímulos daqueles apresentados para o primeiro experimento de percepção, só que agora as sentenças que compunham os estímulos não eram mais filtradas, eram naturais. O objetivo desses dois experimentos foi observar a diferença de percepção entre as informações apenas tonais e as informações tonais (suprassegmentais) e segmentais.

Os testes foram montados via script do Praat (BOERSMA, WEENINK, 2016). Para realizá-lo, o ouvinte colocava um headfone e, na tela do computador, a partir da escuta de cada estímulo, selecionava a resposta 
mais adequada. O ouvinte tinha como possibilidades de resposta: manezinho ou outro dialeto, conforme Figura 5. Era possível repetir a escuta do estímulo, e o tempo de resposta também foi coletado.

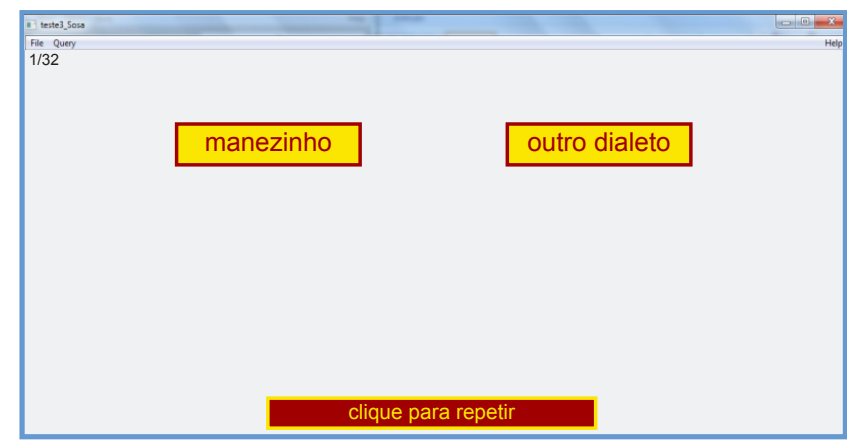

Figura 5. Tela do primeiro teste de percepção com as possibilidades de resposta.

Dos nove ouvintes que realizaram os testes de percepção, três eram florianopolitanos e seis de outras localidades catarinenses (Blumenau, Itajaí e Biguaçu). Os resultados desses dois testes de percepção estão descritos na seção a seguir.

\section{Há uma melodia que caracterize o falar "manezinho"? - os experimentos de percepção}

Com o objetivo de verificar se o contorno entonacional aqui caracterizado como "manezinho" poderia ser percebido apenas pelas informações tonais, elaboramos o primeiro teste de identificação. Eram resultados esperados as seguintes situações:

a) quando o ouvinte escutasse um estímulo referente às 17 sentenças que apresentavam o contorno entonacional caracterizado como "manezinho" e apontasse como resposta manezinho;

b) quando o ouvinte escutasse um estímulo referente a sentenças produzidas por falantes de outros dialetos, como as 10 distratoras, ou referente às cinco sentenças com configurações não "manezinhas" e, nesses casos, apontasse como resposta outro dialeto.

$\mathrm{Na}$ Tabela 1, apresentamos os resultados do primeiro teste de identificação considerando cada um dos estímulos e seus respectivos números de respostas esperadas, conforme os critérios (a) e (b), mostrados anteriormente. $\mathrm{Na}$ notação dos estímulos, os três primeiros símbolos correspondem à identificação do sujeito, o quarto símbolo ao sexo (Feminino e Masculino) e os dois últimos, à localidade do sujeito (OD refere-se a estímulos de outros dialetos e FM aos estímulos do falar "manezinho").
Tabela 1. Resultados do primeiro teste de percepção ${ }^{5}$.

\begin{tabular}{cccc}
\hline Estímulos & Número de RE & $\begin{array}{c}\text { Total de } \\
\text { respostas }\end{array}$ & \% de RE \\
\hline S11FOD1a & 9 & 9 & 100 \\
S11FOD2a & 6 & 9 & 67 \\
S11FOD3a & 8 & 9 & 89 \\
S11FOD4a & 8 & 9 & 89 \\
S11FOD5a & 8 & 9 & 89 \\
S12MOD1a & 5 & 9 & 56 \\
S12MOD2a & 5 & 9 & 56 \\
S12MOD3a & 6 & 9 & 67 \\
S12MOD4a & 6 & 9 & 67 \\
S12MOD5a & 5 & 9 & 56 \\
S05MFM1b & 6 & 9 & 67 \\
S05MFM2a & 6 & 9 & 67 \\
S05MFM3a & 3 & 9 & 33 \\
S05MFM4a & 8 & 9 & 89 \\
S05MFM5a* & 6 & 9 & 67 \\
S05MFM6a & 6 & 9 & 67 \\
S05MFM7a & 4 & 9 & 44 \\
S05MFM8a & 5 & 9 & 56 \\
S07FFM1a & 4 & 9 & 44 \\
S07FFM2a & 9 & 9 & 100 \\
S07FFM3a* & 3 & 9 & 33 \\
S07FFM4a & 4 & 9 & 44 \\
S07FFM5a & 6 & 9 & 67 \\
S07FFM6a* & 8 & 9 & 89 \\
S07FFM7a* & 7 & 9 & 33 \\
S07FFM9a & 3 & 9 & 56 \\
S09FFM1a & 9 & 9 & 99 \\
S09FFM2a* & 3 & 9 & 9 \\
S09FFM3a & 5 & 9 & 9 \\
S09FFM4a & 8 & 9 & 9 \\
S09FFM5a & 8 & 9 & 9 \\
S09FFM6a & 8 & 9 & 9 \\
\hline & & 9 & 9 \\
\hline
\end{tabular}

A média geral de respostas esperadas foi de $67,91 \%$. Obtivemos $71 \%$ de respostas esperadas superiores a $50 \%$. Dentre os estímulos que apresentavam o contorno característico do falar "manezinho", tivemos uma média de respostas esperadas de 66,71\%. Dos cinco estímulos que eram do falar "manezinho", mas não apresentavam esse contorno característico, a média de respostas esperadas cai para $60 \%$. Dos 22 estímulos do falar "manezinho", apenas cinco deles tiveram percentual de respostas esperadas menor do que $50 \%$ e dos que apresentaram apenas 33\% de respostas esperadas, dois deles eram de sentenças que não apresentavam o contorno entonacional característico do falar "manezinho". Esse resultado nos parece bastante consistente, considerando que nesse teste os ouvintes tinham informações apenas tonais (suprassegmentais), sem informação segmental.

\footnotetext{
Os asteriscos indicam informações tonais referentes aos estímulos cujos contornos não foram caracterizados como "manezinhos" e RE significa Respostas Esperadas
} 
E corrobora os achados deste estudo no sentido de que há uma entoação que identifica o falar "manezinho".

Os estímulos distratores tiveram média de respostas esperadas de $73,33 \%$. Se separarmos os estímulos por sujeito, S11 foi considerado como estímulo de outro dialeto para $86,67 \%$ de suas produções e $\mathrm{S} 12$, para $60 \%$.

Reiteramos que esses resultados são referentes a estímulos que continham apenas as informações suprassegmentais, as quais os ouvintes não estão acostumados. O tempo de resposta para esse primeiro teste variou entre $2,1 \mathrm{~s}$ e $56,68 \mathrm{~s}$.

Na Tabela 2, são exibidos os resultados do segundo teste de identificação considerando cada um dos estímulos e seus respectivos números de respostas esperadas, também levando em conta os critérios (a) e (b), apresentados anteriormente.

Tabela 2. Resultados do segundo teste de percepção6 .

\begin{tabular}{|c|c|c|c|}
\hline Estímulos & Número de RE & $\begin{array}{c}\text { Total de } \\
\text { respostas }\end{array}$ & $\%$ de RE \\
\hline S11FOD1a & 8 & 9 & 89 \\
\hline S11FOD2a & 9 & 9 & 100 \\
\hline S11FOD3a & 8 & 9 & 89 \\
\hline S11FOD4a & 9 & 9 & 100 \\
\hline S11FOD5a & 6 & 9 & 67 \\
\hline S12MOD1a & 9 & 9 & 100 \\
\hline S12MOD2a & 9 & 9 & 100 \\
\hline S12MOD3a & 9 & 9 & 100 \\
\hline S12MOD4a & 7 & 9 & 78 \\
\hline S12MOD5a & 9 & 9 & 100 \\
\hline S05MFM1b & 9 & 9 & 100 \\
\hline S05MFM2a & 9 & 9 & 100 \\
\hline S05MFM3a & 8 & 9 & 89 \\
\hline S05MFM4a & 7 & 9 & 78 \\
\hline S05MFM5a* & 4 & 9 & 44 \\
\hline S05MFM6a & 8 & 9 & 89 \\
\hline S05MFM7a & 6 & 9 & 67 \\
\hline S05MFM8a & 7 & 9 & 78 \\
\hline S07FFM1a & 9 & 9 & 100 \\
\hline S07FFM2a & 8 & 9 & 89 \\
\hline S07FFM3a* & 8 & 9 & 89 \\
\hline S07FFM4a & 9 & 9 & 100 \\
\hline S07FFM5a & 9 & 9 & 100 \\
\hline S07FFM6a* & 9 & 9 & 100 \\
\hline S07FFM7a* & 8 & 9 & 89 \\
\hline S07FFM9a & 9 & 9 & 100 \\
\hline S09FFM1a & 5 & 9 & 56 \\
\hline S09FFM2a* & 9 & 9 & 100 \\
\hline S09FFM3a & 8 & 9 & 89 \\
\hline S09FFM4a & 8 & 9 & 89 \\
\hline S09FFM5a & 7 & 9 & 78 \\
\hline S09FFM6a & 7 & 9 & 78 \\
\hline
\end{tabular}

\footnotetext{
Os asteriscos indicam informações tonais referentes aos estímulos cujos contornos não foram caracterizados como "manezinhos" e RE significa Respostas Esperadas.
}

A média geral de respostas esperadas foi de $88,19 \%$. Obtivemos $94 \%$ de respostas esperadas superiores a $50 \%$. Dentre os estímulos que apresentavam o contorno entonacional característico do falar "manezinho", tivemos uma média de respostas esperadas de 86,93\%. Dos cinco estímulos que eram do falar "manezinho", mas não apresentavam o seu contorno entonacional característico, a média de respostas esperadas decresce para $84,44 \%$. Esse valor cai pouco, uma vez que agora, além das informações suprassegmentais, o ouvinte tem informações segmentais para balizar sua avaliação dos estímulos. No cômputo geral, seria esperado um aumento dos percentuais, o que ocorreu.

Dos 22 estímulos do falar "manezinho", apenas um deles teve percentual de respostas esperadas menor do que $50 \%$ e refere-se a um dos estímulos do falar "manezinho" que, porém, não apresentava o contorno entonacional característico aqui descrito. Os estímulos distratores tiveram média de respostas esperadas de $92,22 \%$. O tempo de resposta para esse segundo teste variou entre 2,0 s e 44,48 s.

Comparando os resultados do primeiro e do segundo testes, vemos que há um aumento no percentual de acertos no segundo teste, o que seria esperado, haja vista que agora o ouvinte tem, além das informações suprassegmentais, informações segmentais que auxiliam no seu julgamento. Levando em conta o tempo de resposta, para o segundo teste, $58 \%$ das respostas tinha tempo de reação inferior a 10 s e, para o primeiro teste, $48 \%$.

\section{Algumas conclusões}

Efetivamente, confirmamos (i) que o contorno entonacional do falar "manezinho" é realmente um marcador de identidade; (ii) que é reconhecido pelos falantes como um traço que identifica o falar "manezinho"; (iii) que tem características fonéticas próprias. O mais relevante deste estudo foi descrever um contorno entonacional que os falantes florianopolitanos reconhecem como específico do falar "manezinho". A consistência dos resultados dos experimentos de percepção confirma a hipótese de que há um contorno entonacional que caracteriza o falar "manezinho".

No entanto, a pragmática e a semântica, relativas a este contorno entonacional do falar "manezinho", precisam ser mais claramente explicadas nas suas implicações discursivas, colocando os exemplos dentro do contexto, com o objetivo de verificar se existe distribuição complementar deste contorno entonacional declarativo (com possível sentido de finalidade, ou de término do turno) com o contorno mais frequente do $\mathrm{PB}, \mathrm{o} \mathrm{H}+\mathrm{L} * \mathrm{~L} \%$. Esse contorno considerado como o mais recorrente no PB também ocorre nos dados do falar "manezinho", e 
um de nossos próximos passos será comparar essas duas possibilidades de contorno entonacional e mais finamente estabelecer o contexto da importante queda tonal de uma oitava, presente no contorno aqui definido como "manezinho".

Foi interessante notar como alguns informantes da nossa amostra, mesmo usando sistematicamente o contorno entonacional que descrevemos nos contextos declarativos finais, apresentam uma porcentagem importante de contornos já descritos como mais recorrentes no $\mathrm{PB}-\mathrm{H}+\mathrm{L} * \mathrm{~L} \%$. Isso pode indicar uma possível mudança linguística ou um nivelamento dialetal. Estudos futuros mais aprofundados sobre o tema poderão confirmar ou não essas hipóteses.

$\mathrm{O}$ fato de a nossa variável ser associada a variedades não urbanas, que, em tempo aparente, podem ter perdido vitalidade, indicaria o caminho de um dialeto tradicional - possivelmente conservador de formas arcaicas. E esse dialeto estaria passando por uma mudança através de processos de normalização e estandarização.

Inovamos integrando variáveis prosódicas no estudo da variação sociofonética e dialetológica, em uma variedade peculiar do PB, com detalhes fonéticos precisos. Devemos buscar agora avançar em direção ao estudo da semântica das funções e usos, dos padrões de realizações entonacionais gerais do falar "manezinho".

\section{Referências}

BOERSMA, Paul; WEENINK, David. Praat: doing phonetics by computer [Computer program]. Version 6.0.14, Disponível em: <http://www.praat.org>. Acesso em: fev. 2016.

LOOZE, Céline de; HIRST, Daniel. The OMe (OctaveMedian) scale: a natural scale for speech prosody. In: CAMPBELL, Nick; GIBBON, Dafydd; HIRST, Daniel (Ed.). Social and Linguistic Speech Prosody 7. Proceedings of the 7th International Conference on Speech Prosody. Trinity College, Dublin, Ireland, May 2014.

FROTA, Sonia; PRIETO, Pillar (Ed.). Intonation in Romance. Oxford University Press, 2015.
FURLAN, Osvaldo. Influência açoriana no português do Brasil em Santa Catarina. Florianópolis: UFSC, 1989.

LADD, Robert. Intonational phonology. Cambridge: Cambridge University Press. 2008.

PRIETO, Pilar. Las teorías linguísticas de la entonación. Teorías de la entonación. Barcelona: Ariel, 2003. p. 13-33.

MORAES, João Antônio. The pitch accents in brazilian portuguese: analysis by synthesis. In: Proceedings of the Fourth Conference on Speech Prosody. Campinas: Unicamp, 2008. p. 389-397.

NUNES, Vanessa Gonzaga; SEARA, Izabel Christine. O falar florianopolitano e lageano: uma análise perceptual. In: III COLÓQUIO BRASILEIRO DE PROSÓDIA DA FALA, III, 2011, Belo Horizonte. Anais ... 2011. p. 01-01.

NUNES, Vanessa Gonzaga. Análises entonacionais de sentenças afirmativas e interrogativas totais nos falares florianopolitano e lageano. 2011. 178 f. Dissertação (Mestrado em Linguística) - Universidade Federal de Santa Catarina, Florianópolis, 2011.

SEARA, Izabel Christine; SILVA, Maria Cristina Figueiredo; BERRI, André. A entoação do SN-Sujeito no PB falado em Florianópolis: sentenças afirmativas e interrogativas totais. Revista Internacional de Linguística Iberoamericana, v. 9, p. 157-168, 2011.

SEARA, Izabel Christine; COUTO, Letícia Rebollo. Entoação de frases declarativas e interrogativas no falar fluminense e catarinense. In: XVI Congreso Internacional de la ALFAL, 2011, Alcalá de Henares (Espanha). Actas XVI Congreso Internacional de la ALFAL. Alcalá de Henares: Universidad de Alcalá, 2011. Vol. 1. p. 01-07.

SOSA, Juan Manuel. La notación tonal del español en el modelo Sp_ToBI. In: PRIETO, P. (Ed.). Teorías de la entonación. Barcelona: Ariel, 2003. p. 185-208.

VARSUL - Projeto de Variação Linguística na Região Sul do Brasil, Universidade Federal de Santa Catarina, [1990-2012]. Disponível em: <http://www.varsul.org.br/>. Acesso em: 20 abr. 2016.

Recebido: 30 de setembro de 2016

Aprovado: 08 de março de 2017

Contato: izabels@linse.ufsc.br sosa@sfu.ca 